\title{
Short communication: Parapoxvirus and Orthopoxvirus coinfection in milk of naturally infected cows
}

\author{
Izabelle S. Rehfeld, Ana Luiza S. Fraiha, Ana Carolina D. Matos, Aristóteles G. Costa, Grazielle C. F. Gallinari, \\ Érica A. Costa, Maria Isabel M. C. Guedes, and Zélia Inês P. Lobato ${ }^{1}$ \\ Laboratório de Pesquisa em Virologia Animal, Departamento de Medicina Veterinária Preventiva, Escola de Veterinária, \\ Universidade Federal de Minas Gerais, Brazil 31.270-901
}

\section{ABSTRACT}

Several studies have shown the occurrence of poxvirus infections associated with exanthematic lesions in cattle from many Brazilian states. Coinfection between viruses belonging to 2 genera, Orthopoxvirus (OPXV) and Parapoxvirus (PPV), was already identified from the lesions of affected cows and humans. The DNA and infectious viral particles of Vaccinia virus, an OPXV, have been detected in milk of naturally and experimentally infected cows. However, to date no reports have described the detection of Pseudocowpox virus, a PPV, in milk. Thus, we investigated the presence of PPV and OPXV in milk samples obtained from dairy cows from a Brazilian region with exanthematic disease outbreaks. From 2011 to 2014, 6 dairy farms with exanthematic disease outbreaks involving dairy cows, calves, and humans were visited. Twelve crusts of cows' teat lesions and 60 milk samples were collected. The crusts and milk samples were analyzed by PCR to detect OPXV or PPV DNA. According to the analyzed crusts, we detected PPV infection in 4 of the 6 visited farms, from which we investigated the PPV contamination in milk. From the 40 milk samples tested, PPV DNA was detected in 12 samples. Of these milk samples, 8 were positive for both PPV and OPXV. This is the first report of PPV DNA detection in milk samples from affected cows, indicating that the virus may be present in milk and potentially contaminating dairy products associated or not with OPXV. In addition to the lesions caused by direct contact, the presence of 2 or more poxvirus species in milk showed that the effect of zoonotic exanthematic diseases on public health and animal husbandry is relevant and cannot be overlooked. Key words: Parapoxvirus, Orthopoxvirus, coinfection, milk

Received October 16, 2017.

Accepted May 8, 2018.

${ }^{1}$ Corresponding author: ziplobato@gmail.com

\section{Short Communication}

Pseudocowpox or milkers' nodule is a zoonotic and exanthematic disease of cattle caused by Pseudocowpox virus (PCPV), which belongs to the Parapoxvirus (PPV) genus. The infection caused by PCPV is characterized by a vesicular-pustular self-limiting disease, usually with lesions observed on the teats and udder of cows and the oral cavity and muzzles of calves as well as the hands of humans (Abrahão et al., 2010b; Cargnelutti et al., 2012; de Sant'Ana et al., 2012). The lesions start as blisters and papules and progress to ulcers and scabs, which are clinically indistinguishable from those caused by bovine vaccinia, caused by Vaccinia virus (VACV), a member of the Orthopoxvirus (OPXV) genus. Moreover, the lesions in the oral cavity and muzzles of calves as well as on human hands could be caused by another PPV, Bovine papular stomatitis virus. Bovine papular stomatitis virus and PCPV are the 2 species within the PPV genus that affect cattle.

Previous studies showed the occurrence of poxvirus infections in several Brazilian states, and VACV is the most commonly detected species. More recent data on the pathogenesis and transmission of VACV are available (Rehfeld et al., 2013, 2015; Rivetti et al., 2013; de Oliveira et al., 2015). However, studies on PPV infection in cattle from Brazil are limited, and usually they are case reports (Abrahão et al., 2010b; Cargnelutti et al., 2012, 2014; de Sant'Ana et al., 2012, 2013; Alves et al., 2016; Laguardia-Nascimento et al., 2016). There are studies that showed the detection of VACV DNA and infectious viral particles in the milk of naturally and experimentally infected cows (Abrahão et al., 2009; de Oliveira et al., 2015). However, the presence of PPV in cow milk samples has not been described so far. This study aimed to investigate PPV and OPXV coinfection and possible contamination with PPV in milk samples from cows with exanthematic lesions in the teats belonging to farms with exanthematic disease outbreaks.

From 2011 to 2014, 6 dairy farms with exanthematic disease outbreaks involving dairy cows, calves, and hu- 
Table 1. Detection of Parapoxvirus (PPV) B2L gene by PCR in crusts and milk samples collected from cows in 6 farms with exanthematic disease outbreaks and detection of PPV-Orthopoxvirus (OPXV) coinfection in milk samples

\begin{tabular}{|c|c|c|c|c|c|c|c|c|c|}
\hline \multirow[b]{2}{*}{ Farm } & \multicolumn{3}{|c|}{ PPV crusts } & \multicolumn{3}{|c|}{ PPV milk } & \multicolumn{3}{|c|}{$\begin{array}{c}\text { PPV-OPXV } \\
\text { coinfection in milk }\end{array}$} \\
\hline & Positive $^{1}$ & Total & $\%$ & Positive & Total & $\%$ & Positive & Total & $\%$ \\
\hline 1 & 2 & 2 & 100 & 3 & 10 & 30 & 1 & 3 & 33.3 \\
\hline 2 & 0 & 2 & 0 & & $\mathrm{NP}^{2}$ & & & $\mathrm{NP}$ & \\
\hline 3 & 2 & 2 & 100 & 3 & 10 & 30 & 3 & 3 & 100 \\
\hline 4 & 1 & 2 & 50 & 4 & 10 & 40 & 2 & 4 & 50 \\
\hline 5 & 0 & 2 & 0 & & NP & & & $\mathrm{NP}$ & \\
\hline 6 & 2 & 2 & 100 & 2 & 10 & 20 & 2 & 2 & 100 \\
\hline Total & 7 & 12 & 58.3 & 12 & 40 & 30 & 8 & 12 & 66.7 \\
\hline
\end{tabular}

mans were visited (F1-F6). These farms are located in Minas Gerais State, which is the major milk producer in Brazil. These farms, owned by small milk producers, are located in the small region of Serro, a cheeseproducing area of Minas Gerais State and a place where manual milking is still performed in some farms and cheeses are made with raw milk.

To identify the etiological agent(s) involved in the exanthematic disease outbreaks, crusts from 2 cows with clinical signs from each farm were randomly collected, totalizing 12 crusts. Crust samples were macerated and diluted in 1:10 PBS. Additionally, 10 cows with clinical signs from each farm were randomly selected, and handmilked samples were collected from each cow, placed in 100-mL sterile bottles, and diluted in 1:3 PBS. In total, 60 milk samples were collected (10 from each farm).

Subsequently, crust samples were subjected to DNA extraction using a commercial kit, Wizard Genomic DNA Purification System (Promega, Madison, WI). The OPXV vgf gene was detected by a semi-nested PCR as described by Abrahão et al. (2010a). To investigate the presence of PPV DNA, a conventional PCR was performed as described by Inoshima et al. (2000), which amplified the gene fragment B2L that is conserved among species belonging to the PPV genus. Two generic primers, including PPP-1 forward $\left(5^{\prime}-3^{\prime}\right.$ GTCGTCCACGATGAGCAGCT) and PPP-4 reverse (5'-3'TACGTGGGAAGCGCCTCGCT), were used to amplify a 594-bp fragment.

Orthopoxvirus DNA was detected in the crust samples from the 12 tested cows, confirming the OPXV infection in all 6 farms. However, PPV DNA was detected in 7 out of the 12 scabs $(58.3 \%)$, indicating OPXV and PPV coinfection in 4 of the 6 visited farms (Table 1). The PPV milk contamination was investigated in the $4 \mathrm{PPV}$-positive farms, totaling 40 milk samples. Therefore, from the 40 milk samples analyzed for the presence of PPV DNA, 30\% (12/40) tested positive for
PPV. Of these 12 PPV-positive milk samples, 66.7\% (8/12) were positive for both PPV and OPXV DNA (Table 1), confirming a coinfection by both viruses in the milk samples as well.

Few studies about PPV in cattle, conducted in Brazil, are available. However, it seems that these viruses are widespread across the country because they have been detected in the southeastern region (Abrahão et al., 2010b), the southern region (Cargnelutti et al., 2012), the midwestern region (de Sant'Ana et al., 2012, 2013; Laguardia-Nascimento et al., 2016), and the northern region (Cargnelutti et al., 2014; Alves et al., 2016; Laguardia-Nascimento et al., 2016) of the country. Moreover, PPV and OPXV coinfections have previously been described in lesion samples from cows and humans during bovine vesicular disease outbreaks in Brazil (Abrahão et al., 2010b; de Sant'Ana et al., 2013). The origin and effect of these coinfections in the pathogenesis of the disease are still unclear, although the infection that is associated with 2 or more viruses is believed to cause injuries of increased severity with pronounced inflammation (Abrahão et al., 2010b; Cargnelutti et al., 2014).

Herein we report the first detection of PPV in milk from affected dairy cows, indicating that the virus may be present in milk and potentially contaminating dairy products associated or not with OPXV. Thus, corroborating previous findings of OPXV infection in milk and cheese from affected cows (de Oliveira et al., 2015), PPV milk contamination calls attention to the potential risk of PPV transmission to humans through the ingestion or handling of contaminated dairy products.

Future studies on the prevalence of PPV in Brazilian cattle herds, the detection of PPV in milk from cows subclinically infected with PPV, the frequency of coinfection with OPXV and PPV, and the methods of prevention and control of bovine exanthematic diseases caused by poxvirus should be conducted. The 
prevalence of such diseases in Brazil is not known because they are underreported. However, the occurrence of those diseases is widespread in the country and is responsible for major economic losses in dairy farming and problems related to public health.

In the present study, milk samples from cows with exanthematic lesions caused by poxvirus may be contaminated with 2 or more viral species that belong to the PPV and OPXV genera. In addition to the injuries caused by direct contact, the presence of 2 or more poxvirus species in milk showed that the effect of these zoonotic diseases on public health and animal husbandry is relevant and cannot be overlooked.

\section{ACKNOWLEDGMENTS}

This study was supported by the Conselho Nacional de Desenvolvimento Científico e Tecnológico (CNPq, Brazil), Coordenação de Aperfeiçoamento de Pessoal de Nível Superior (CAPES, Brazil), Fundação de Amparo à Pesquisa do Estado de Minas Gerais (FAPEMIG, Minas Gerais, Brazil), Instituto Mineiro de Agropecuária (IMA, Minas Gerais, Brazil), Pró-Reitoria de Pesquisa/UFMG (Belo Horizonte, Minas Gerais, Brazil), and the owners of the visited farms.

\section{REFERENCES}

Abrahão, J. S., B. P. Drumond, G. S. Trindade, A. T. da Silva-Fernandes, J. M. Ferreira, P. A. Alves, R. K. Campos, L. Siqueira, C. A. Bonjardim, P. C. Ferreira, and E. G. Kroon. 2010a. Rapid detection of Orthopoxvirus by semi-nested PCR directly from clinical specimens: A useful alternative for routine laboratories. J. Med. Virol. 82:692-699.

Abrahão, J. S., T. M. Oliveira, R. K. Campos, M. C. Madureira, E. G. Kroon, and Z. I. P. Lobato. 2009. Bovine vaccinia outbreaks: Detection and isolation of Vaccinia virus in milk samples. Foodborne Pathog. Dis. 6:1141-1146.

Abrahão, J. S., A. T. Silva-Fernandes, F. L. Assis, M. I. Guedes, B. P. Drumond, J. A. Leite, L. F. Coelho, F. Turrini, F. G. Fonseca, Z. I. P. Lobato, M. Madureira, P. C. Ferreira, C. A. Bonjardim, G. S. Trindade, and E. G. Kroon. 2010b. Human Vaccinia virus and Pseudocowpox virus coinfection: Clinical description and phylogenetic characterization. J. Clin. Virol. 48:69-72.
Alves, P. A., P. O. Figueiredo, C. H. S. de Oliveira, J. D. Barbosa, D. H. S. Lima, H. A. Bomjardim, N. S. Silva, K. F. Campos, C. M. C. Oliveira, E. F. Barbosa-Stancioli, J. S. Abrahão, E. G. Kroon, and G. de Souza Trindade. 2016. Occurrence of Pseudocowpox virus associated to bovine viral diarrhea virus-1, Brazilian Amazon. Comp. Immunol. Microbiol. Infect. Dis. 49:70-75.

Cargnelutti, J. F., M. M. Flores, F. R. M. Teixeira, R. Weiblen, and E. F. Flores. 2012. An outbreak of pseudocowpox in fattening calves in southern Brazil. J. Vet. Diagn. Invest. 24:437-441.

Cargnelutti, J. F., B. S. Santos, S. N. Lebre, D. N. A. Sodré, R. M. da Silva, R. Weiblen, and E. F. Flores. 2014. Pseudocowpox and papular stomatitis in cattle in the Rondonia state, Brazil. Ciência Rural Santa Maria 44:479-485. (In Portuguese).

de Oliveira, T. M. L., M. I. M. C. Guedes, I. S. Rehfeld, A. C. D. Matos, A. V. Rivetti Jr., P. A. Alves, G. C. F. Galinari, M. M. Cerqueira, J. S. Abrahão, and Z. I. P. Lobato. 2015. Detection of Vaccinia virus in milk: Evidence of a systemic and persistent infection in experimentally infected cows. Foodborne Pathog. Dis. 12:898-903.

de Sant'Ana, F. J. F., F. A. A. Leal, R. E. Rabelo, V. A. Vulcani, C. A. Moreira Jr., J. F. Cargnelutti, and E. F. Flores. 2013. Coinfection by Vaccinia virus and an Orf virus-like Parapoxvirus in an outbreak of vesicular disease in dairy cows in Midwestern Brazil. J. Vet. Diagn. Invest. 25:267-272.

de Sant'Ana, F. J. F., R. E. Rabelo, V. A. Vulcani, J. F. Cargnelutti, and E. F. Flores. 2012. Bovine papular stomatitis affecting dairy cows and milkers in Midwestern Brazil. J. Vet. Diagn. Invest. 24:442-445.

Inoshima, Y., A. Morooka, and H. Sentsui. 2000. Detection and diagnosis of Parapoxvirus by polymerase chain reaction. J. Virol. Methods 84:201-208.

Laguardia-Nascimento, M., E. B. Sales, M. R. Gasparini, N. M. de Souza, J. A. da Silva, G. G. Souza, F. R. Carani, A. F. dos Santos, A. V. Rivetti Jr., M. F. Camargos, and A. A. Fonseca Jr.. 2016. Detection of multiple viral infections in cattle and buffalo with suspected vesicular disease in Brazil. J. Vet. Diagn. Invest. $28: 377-381$.

Rehfeld, I. S., M. I. Guedes, A. C. Matos, T. M. de Oliveira, A. V. Rivetti Jr., A. C. Moura, P. R. Paes, L. A. do Lago, E. G. Kroon, and Z. I. P. Lobato. 2013. Clinical, hematological and biochemical parameters of dairy cows experimentally infected with Vaccinia virus. Res. Vet. Sci. 95:752-757.

Rehfeld, I. S., M. I. M. C. Guedes, A. L. S. Fraiha, A. G. Costa, A. C. D. Matos, A. T. Fiuza, and Z. I. P. Lobato. 2015. Vaccinia virus: Transmission through experimentally contaminated milk using murine model. PLoS One 10:e0127350.

Rivetti, A. V., M. I. M. C. Guedes, I. S. Rehfeld, T. M. Oliveira, A. C. D. Matos, J. S. Abrahão, E. G. Kroon, and Z. I. P. Lobato. 2013. Bovine vaccinia, a systemic infection: Evidence of fecal shedding, viremia and detection in lymphoid organs. Vet. Microbiol. 162:103-111. 